\title{
Global improvements in Years of Good Life since 1950
}

\author{
Erich Striessnig $^{1, *}$, Claudia Reiter ${ }^{1}$ and Anna Dimitrova ${ }^{2}$
}

\begin{abstract}
Human well-being at the national aggregate level is typically measured by GDP per capita, life expectancy or a composite index such as the HDI. A more recent alternative is the Years of Good Life (YoGL) indicator presented by Lutz et al. $(2018 ; 2021)$. YoGL represents a refinement of life expectancy in which only those person-years in a life table are counted that are spent free from material (1), physical (2) or cognitive limitations (3), while being subjectively perceived as satisfying (4). In this article, we present the reconstruction of YoGL to 1950 for 140 countries. Since life expectancy - as reported by the UN World Population Prospects in fiveyearly steps - forms the basis of our reconstruction, the presented dataset is also available on a five-yearly basis. In addition, like life expectancy, YoGL can be flexibly calculated for different sub-populations. Hence, we present separate YoGL estimates for women and men. Due to a lack of data, only the material dimension can be reconstructed based directly on empirical inputs since 1950 . The remaining dimensions are modelled based on information from the more recent past.
\end{abstract}

Keywords: Years of Good Life; well-being indicator; human development; survival; basic needs

\section{Introduction}

Researchers trying to shed light on the question of whether there have been global improvements in the quality of life (QOL) are typically limited to studying either (1) just the most recent past, as the available data allow for more comprehensive international comparisons; or (2) just a small number of selected countries, mostly

\footnotetext{
${ }^{1}$ Department of Demography, University of Vienna, Wittgenstein Centre for Demography and Global Human Capital (IIASA, OeAW, University of Vienna), Vienna, Austria

${ }^{2}$ Scripps Institution of Oceanography, University of California San Diego, La Jolla, CA, USA

${ }^{*}$ Correspondence to: Erich Striessnig, erich.striessnig@univie.ac.at
} 
in the developed world; or (3) just a narrow set of often not very sophisticated indicators that can be calculated based on data that have already been collected over longer periods of time. The QOL indicators for which longer time series do exist, and that are available in harmonized form over a large number of countries, include life expectancy and GDP per capita. Both of these indicators have their shortcomings (Stiglitz et al. 2010; Ghislandi et al. 2019), and can give us only limited insight into how QOL has actually changed over time. In addition, neither of the two indicators include information on national differences in subjective wellbeing, which is not represented well in measures of affluence or longevity (Easterlin 1974; Helliwell et al. 2012).

To overcome these challenges, researchers have recently proposed a new indicator that focuses on the number of Years of Good Life (YoGL) that people can expect to live as members of different populations (Lutz et al. 2021). The YoGL indicator is based on period life tables that are available for most countries of the world starting in 1950 (United Nations 2019). Yet estimates of how many years people can expect to live do not tell us about the quality of those years in terms of human well-being. Thus, to derive YoGL, the person-years lived in different age brackets according to the life table are weighted by the age-specific proportions of people living years of life without limitations in the dimensions of (1) material, (2) physical, (3) cognitive and (4) subjective well-being (SWB). The first three of these dimensions can be assessed based on objective standards, whereas the fourth dimension is, by definition, subjectively assessed. While exclusively objective assessments of QOL fail to address individual differences in preferences (different people have different utility functions), and exclusively subjective assessments overemphasize those personal preferences, the combination of the two approaches stipulates that a life year lived can only be seen as "a good year" if objective criteria are met and - borrowing from Diener's "hallmarks" of the SWB area (Diener 1984) - if the individual confirms that the assessment is based on his or her own subjective set of weights. Since both the subjective and the objective criteria have to be met, there is no trade-off between the different dimensions at the individual level.

In this article, we present a new dataset containing the reconstruction of YoGL to 1950 for 140 countries of the world. Naturally, not all of the dimensions required for the orthodox calculation of YoGL are available from internationally harmonized datasets for that many countries; thus, we had to relax some of the assumptions made in the original definition of YoGL. In addition, we lack information for all four dimensions for the same set of individuals that goes far enough back into the past. Having this kind of information is important to account for possible correlations between the different dimensions, as in many cases, individuals who fail to fulfill the YoGL criteria on objective grounds will also be dissatisfied with their life from their own subjective point of view. Therefore, after outlining the conceptual approach and relating it to the literature, we discuss our methodological approach aimed at circumventing the problem of individual-level correlation in the absence of individual-level data. We then present the results derived from applying that methodology to the available data, and close with a discussion of the new dataset's implications with regard to changes in QOL since 1950. 


\section{Conceptualization and related work}

The YoGL indicator was first introduced by Lutz et al. (2018) to help with the assessment of the progress made in reaching the Sustainable Development Goals. Viewed from a micro-level perspective, YoGL aims to estimate the remaining years of life an individual can expect to live in a "good" state. However, from a macrolevel perspective, its explicit purpose is to serve as a basis for judging whether long-term development trajectories are sustainable. Therefore, YoGL focuses on the changing composition of populations with regard to characteristics that constitute a society's human well-being in the aggregate (Lutz et al. 2021).

The structure of YoGL is based on different dimensions that are subject to a clear hierarchy, as depicted in Figure 1. First and foremost, survival is considered the essential prerequisite for enjoying any QOL. However, since mere survival cannot sufficiently capture well-being, "good" years of life are counted conditional on meeting minimum standards in both objective and subjective dimensions. Following Desai et al. (1992), the objectively assessable conditions measuring "capable longevity" consist of three sub-dimensions: being out of poverty, being cognitively enabled and having no serious physical disabilities. Life years are considered as good years only if people are above the critical levels in all three of these objective dimensions and in their self-reported overall life satisfaction. This indicator is graphically depicted in Figure 1 as the intersection of capable longevity and years with positive life satisfaction as a subset of the overall years of life. More detailed information about the theoretical foundations of the indicator, as well as a comparison between YoGL and other existing well-being indicators, can be found in Lutz et al. (2018; 2021) and Reiter and Lutz (2019).

When seeking to reconstruct YoGL on a global scale back to 1950, we face problems related to data availability. Internationally harmonized data on subjective well-being are not available before the 1980s, when the World Values Survey was first conducted (Inglehart 1990). Consistent international surveys of people's cognitive and physical skills are not available before the early 2000s, with the start of SHARE (Börsch-Supan et al. 2005) and the WHO's SAGE survey (Kowal et al. 2012). Only the poverty sub-dimension of capable longevity can be reconstructed based on the available economic data.

\subsection{Poverty: conceptualization and application}

Poverty is a multi-dimensional concept that can be understood in either absolute or relative terms. Absolute poverty is concerned with the deprivation of basic human needs, such as nutrition and shelter. In its strongest form, which is also known as "indigence," survival itself is put at risk (Lok-Dessallien 2000). If a person is not able to afford the minimum nutritional requirements necessary for her daily activities, or if she is lacking access to safe drinking water and sanitation, she would be considered to be indigent or in extreme poverty. The concept of relative 
Figure 1:

Dimensions of Years of Good Life indicator of human well-being

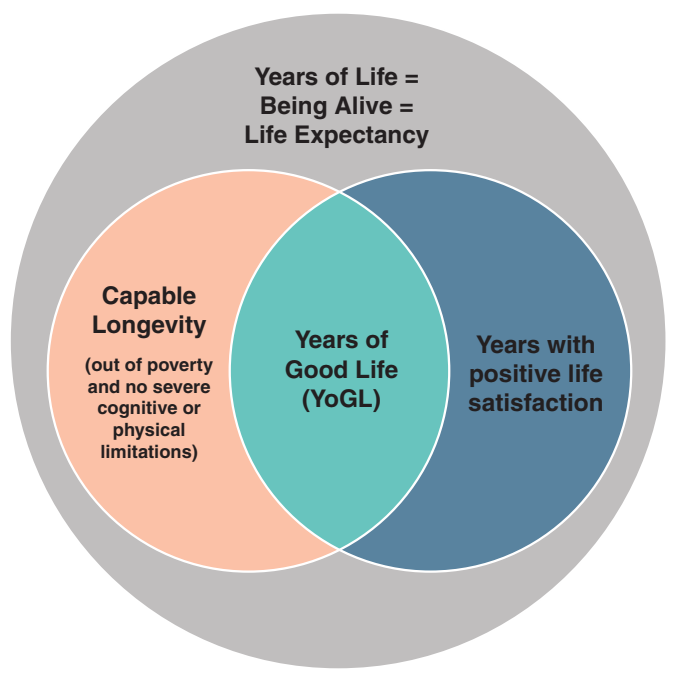

Source: Lutz et al. (2021).

poverty, on the other hand, is concerned with the distribution of resources within a society (Atkinson 1975). In contrast to absolute poverty, relative poverty is not determined by a fixed standard of living, but instead compares different segments of a population, such as people at different ends of the income distribution. The usual definition of relative poverty is living on less than $60 \%$ of the median income after discounting social transfers (European Commission and Statistical Office of the European Union 2018). Thus, relative poverty can vary greatly from country to country, even after adjusting for purchasing power standards (PPS).

Developments in absolute and relative poverty do not necessarily follow the same trend. Therefore, it is possible for a member of a rich society to suffer from relative poverty, while not being in absolute poverty. Moreover, an increase in relative poverty may be accompanied by a decrease in absolute poverty. For example, when a society becomes wealthier, richer households may benefit more from the economic growth than poorer households. In such a case, more households would end up being above the absolute poverty line, even as the gap between the higher and lower income groups becomes larger. Similarly, changes in socioeconomic conditions can affect the absolute and relative aspects of poverty differently (Lok-Dessallien 2000). For example, if prices increase faster than wages, individuals might fall into absolute poverty without changing their relative position, since everyone's standard of living has declined proportionally. Changes in cultural values or status symbols over time may have similar results (Streeten 1990). 
Both absolute and relative poverty are important dimensions to consider when observing social and economic trends and conditions. However, within this paper and in the context of YoGL, we focus exclusively on the dimension of absolute poverty, since our goal is to make cross-country comparisons over time. As Sen has argued $(1983,159)$, there is "an irreducible absolutist core in the idea of poverty," which is why he identified basic material subsistence as one of three "basic capabilities" that jointly determine a person's freedom to achieve well-being (the other two being basic health and cognitive functioning).

While the concept of absolute poverty should be universally applicable, what constitutes a minimum standard of living can, in practice, vary considerably from place to place and over time, as people's underlying value judgements change over time. Hence, in assessing poverty, another major distinction can be made between objective and subjective approaches to poverty (Siposne Nandori 2014). The objective perspective, also known as the welfare approach, is based on the notion that the conditions under which a person would be considered poor can be defined externally; i.e. independently of the value judgements of the person to whom the conditions apply. The subjective approach is, by contrast, not universally applicable, and emphasizes the individual's own perception of poverty. In other words, individuals decide how poor they are based on their subjective beliefs and perceptions. This notion of poverty depends heavily on how much value a person puts on different goods and services, and has at its core a feeling of deprivation about which intersubjective agreement cannot be reached, rather than an externallyprescribed condition of poverty. This feeling is, of course, strongly affected by other members of society against whom individuals measure themselves; i.e. their reference group (Siposne Nandori 2014).

Despite a growing interest in the measurement of subjective poverty, and in integrating the perspective of the poor into poverty research, objective measures of poverty have so far dominated the development literature, and have shaped most poverty reduction policies. Likewise, in YoGL, we also account for poverty as an objective criterion, while differences in individual preferences are entirely accounted for by the subjective well-being dimension.

\section{Data and methods}

To reconstruct YoGL for 140 countries since 1950, we rely on various data sources. Of those sources, the most essential are the UN World Population Prospects (2019), which provide information on longevity in the form of data on age- and sex-specific survival for all countries of the world from 1950 onward. As shown in Lutz et al. (2021), one of the strengths of YoGL is that it can be derived for all kinds of sub-groups of populations, such as by level of educational attainment. However, as consistent education-specific longevity information is available only for a small number of countries - e.g. from Eurostat (2020) - we have chosen to exclude this dimension here. 
As Figure 1 highlights, longevity is not the only precondition for living a good life. For the reconstruction of YoGL, we need additional information on the proportion of life years that meet certain minimum standards in the aforementioned objective dimensions of being out of absolute poverty and enjoying physical and cognitive health, as well as the subjective dimension of life satisfaction. Only one of these four YoGL dimensions - i.e. being out of absolute poverty - can be reconstructed based on the available economic data. For the other three dimensions, we have to apply additional assumptions in order to provide a historical dataset of YoGL around the world.

\subsection{Reconstructing the poverty dimension}

As we outlined above, several attempts have been made to reconstruct past poverty prevalence. Since our goal beyond the scope of the present paper in reconstructing YoGL is to study not just its past development, but also, eventually, its implications for future human well-being under different scenarios, we base our reconstruction of the poverty dimension on the most comprehensive source of information available today: i.e. the World Bank's World Development Indicators (WDI, World Bank 2017). The WDI provide aggregated information based on household surveys on the proportion of people living below $\$ 1.90$ a day for a large number of countries. The longest of those national time series derived from household survey data start in 1981. However, earlier reconstruction efforts go back even further. In the following, we will explain how we make use of the reconstruction conducted by Bourguignon and Morrison (2002) to extend our poverty time series back to 1950. By applying this approach, we can make use of the UN time series on longevity in their entirety.

\subsubsection{Inequality among world citizens (1820-1992)}

Following Roser and Ortiz-Ospina (2013), we combine the WDI data with the information provided by Bourguignon and Morrisson (2002). In their article published in American Economic Review, Bourguignon and Morrison reconstructed global wealth inequality for a large number of territories over the past 200 years. However, for the reasons explained above, our interest lies in the information provided on the 1950-1992 period, which is not fully covered by the contemporary WDI estimates. Bourguignon and Morrison's contributions to our work are income distributions (in deciles) reconstructed for different countries and territories from historical national accounts, as well as from the scarce information available on past distributions of wealth and population size. The individual steps that lead us from those reconstructed income distributions to the proportions of the population living in poverty - i.e. those living on less than $\$ 1.90$ a day - are the following:

1. Apply the income distributions to distribute overall GDP (as reported by Bourguignon and Morrison) across the respective population in any given year 
and country. This gives us the annual income of a representative individual in each income decile.

2. Divide the annual income of a representative individual by 365 to derive the daily disposable income of a representative decile member.

3. Apply linear interpolation to determine the proportion of the population within each income decile who are living above or below the poverty line.

For the population in the higher income deciles, daily disposable income will be far above $\$ 1.90$ a day; thus, everyone in those income deciles will be out of poverty. However, for the population in the lower income deciles, either everyone in the entire decile (if those in the next-higher income decile also live on less than $\$ 1.90$ a day), or at least some individuals in the decile (if those in the next-higher income decile already earn more than $\$ 1.90$ a day), will be living in poverty. By using this approach, we ensure that a disposable income only slightly below the poverty threshold of $\$ 1.90$ a day leads to a lower proportion of the population in that decile living in poverty than if the income level was far below the threshold.

The results are shown in Figure 2 below, in which countries and territories are grouped by world regions. While vast parts of the populations of Europe and North America had escaped from poverty as early as in 1950, many countries in Africa were still far below that target by 1992 . The rapid reduction in poverty among the Asian Tigers is clearly visible, as is the delayed development in South Asia.

Deriving poverty headcount ratios in this way is far from ideal. The limitations that have already been conceded by Bourguignon and Morrison are automatically carried over, especially those pertaining to the poor quality of the historical wealth estimates. Moreover, by using linear interpolation between deciles, we are ignoring potential non-linearities, particularly in the distribution of income within the lower deciles. Still, our method represents the best alternative approach for estimating empirically justified time series that are harmonized over a large number of national territories going back to 1950. In addition, any potential bias induced by our method will be consistent for all territories for which income distributions have been reconstructed by Bourguignon and Morrison. Moreover, going forward from 1992, when the reconstructed time series end, we are not taking the numbers displayed in Figure 2 at face value. Rather, building on the argument of a consistent bias, we rescale these time series to match the more precise WDI headcount ratios in whichever year they first become available for a given country, and apply local polynomial fitting to smooth the transition between the two components of each national series from 1950 to the present. Thus, the reconstruction by Bourguignon and Morrison is only used as an empirical foundation for back-projecting headcount ratios to 1950 based on the more solid evidence from more recent household surveys used by WDI.

Before we can take this additional step, we need to assign the countries of today to the territories that existed in 1820, and for which Bourguignon and Morrison provide information. Not all of these territories still exist as nation states today, and in the case of some formerly unified territories, we can only assume that each of 
Figure 2:

Proportion of population out of poverty; i.e. living on more than $\$ 1.90$ a day. 1950-1992

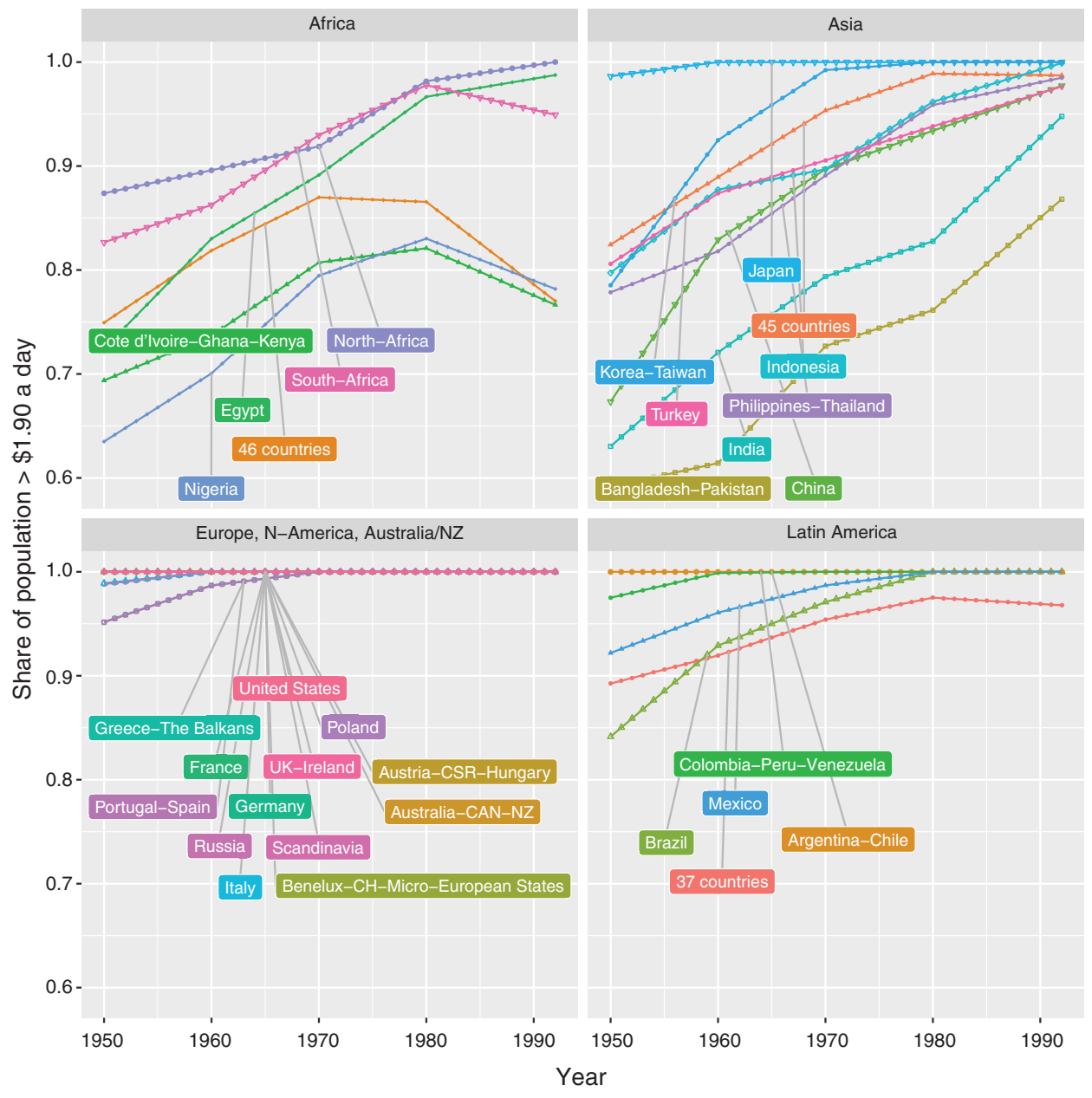

Source: Own calculations based on Bourguignon and Morrisson (2002).

their separate pieces has emerged out of poverty along the same trajectory. While this assumption might be unrealistic - e.g. in the case of the Hapsburg Empire, as the Austrian and Czech parts industrialized earlier than the Hungarian and Slovak parts of the Empire - by 1950, these differences no longer play a big role in terms of the proportion of the population living below the $\$ 1.90$ threshold. In addition, this lack of precision is mitigated by rescaling to the WDI headcount ratios, which already differentiate between these different territories. 
Previous research has shown that gender and poverty are intrinsically linked (Nieuwenhuis et al. 2018). However, as neither the WDI nor Bourguignon and Morrison provide their results disaggregated by gender (or age), for the reconstruction of YoGL, we assume the same poverty rates for males and females, as well as for different age groups. Hence, the gender differences in YoGL reported in this paper are derived from gender-specific life tables, as well as from genderspecific differences in the reconstruction of other sub-dimensions of YoGL, which are described in more detail in Section 3.2.

Reconstructed proportions out of poverty for 140 countries in the world are displayed in Figure 3 for 1950, 1980 and 2010. Besides showing strong improvements in people's living conditions over time, our reconstruction points to large regional differences. While much of Eastern Asia was still experiencing abject poverty in the 1950 s, poverty had diminished noticeably in this part of the world by 2010 . On the other hand, poverty alleviation has not been nearly as successful in most of SubSaharan Africa, where widespread poverty has persisted into the $21^{\text {st }}$ century, with strong implications for the number of good life years that are lost due to poverty.

\subsection{Reconstructing YoGL}

While information about the remaining YoGL dimensions is available for individual countries, it is not available for the vast majority. We therefore resort to reconstructing YoGL based on available survey information from more recent years. In particular, we build our global time series estimates going back to 1950 on existing estimates of YoGL for the 2010-2014 period from 38 countries at various stages of development (Lutz et al. 2021). More specifically, we apply the following procedure to estimate worldwide YoGLs over time:

1. For 38 countries, where data are available for all YoGL dimensions, we estimate YoGL without the poverty dimension. This version of YoGL (henceforth referred to as "YoGL3") is solely based on years lived with positive life satisfaction, with basic cognitive ability and without severe activity limitations. Estimates of YoGL3 provide the basis for the next steps in the procedure.

2. Based on the relationship between the proportion of YoGL3 in life expectancy and total life expectancy at age 20 observed for those 38 countries (see Figure 5), we fit a logistic model to predict YoGL3 for each country and each point in time.

3. In order to consider individual correlations between being out of poverty and the other three YoGL dimensions, we calculate an adjustment factor representing the ratio between the complete YoGL indicator and YoGL3 times the share out-of-poverty for the 38 benchmark countries. As this ratio varies strongly with poverty prevalence (see Figure 6), we estimate the adjustment factor based on the country-specific poverty rates. 


\section{Figure 3:}

Fitted proportion of population living above $\$ 1.90$ a day. 1950, 1980, 2010
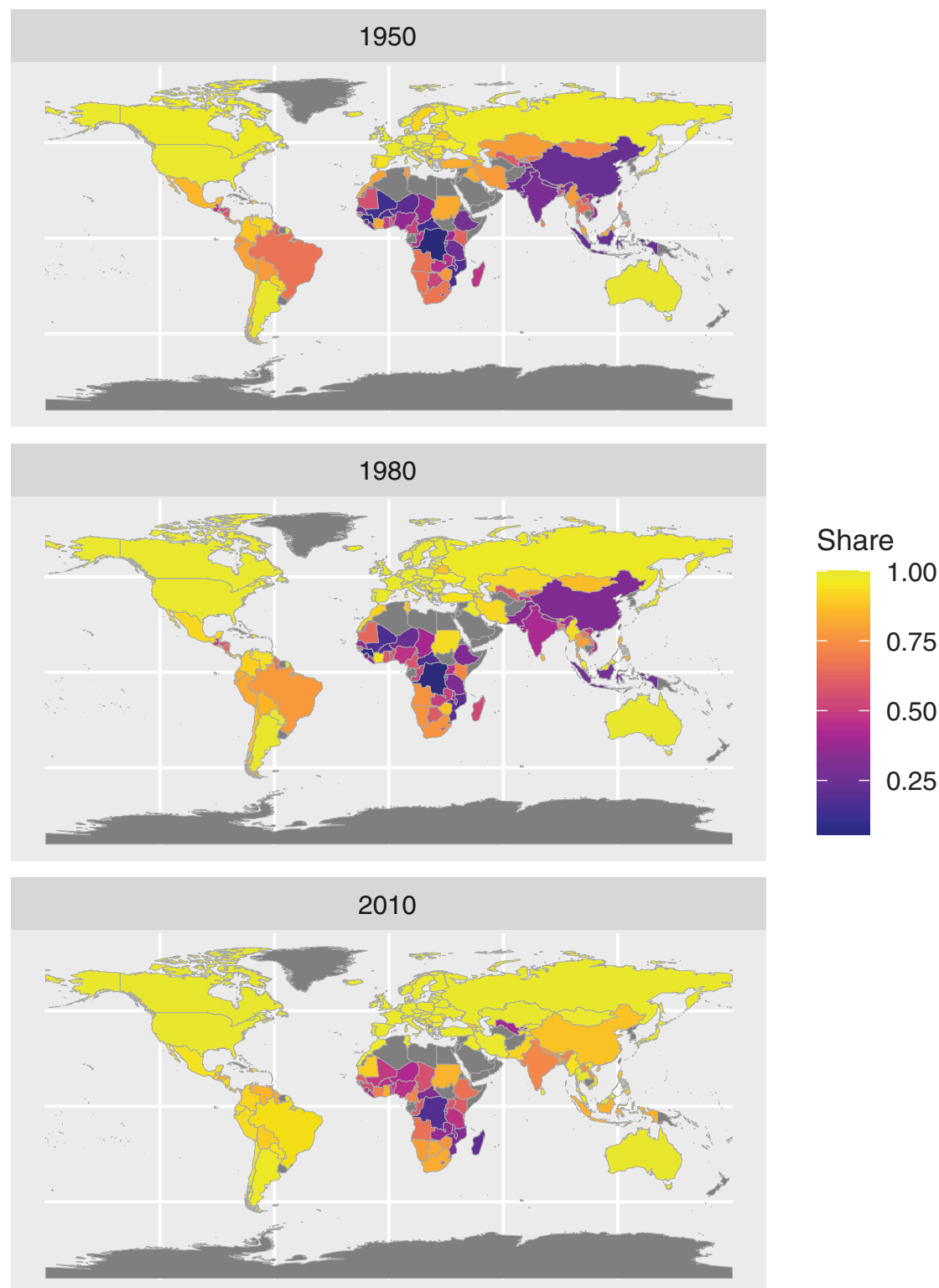

Source: Own calculations based on Bourguignon and Morrisson (2002) and WDI (World Bank 2017). 
4. Finally, YoGL at age 20 is calculated by multiplying the predicted YoGL3 by the estimates of the proportions out-of-poverty displayed in Figure 3, corrected by the adjustment factor to consider individual correlations.

In the following sections, each step will be described in more detail.

\subsubsection{YoGL3 for 38 benchmark countries}

The first step in our estimation, the calculation of YoGL3 for 38 benchmark countries, follows the same steps as the calculation of YoGL. Relying on survey data, we calculate country-specific proportions of individuals above the three remaining dimensions of YoGL by five-year age groups and gender. YoGL3 is then derived based on demographic life table methods (Sullivan method) in which person-years lived at each age are multiplied by age-specific prevalence rates. For more details on the calculation of YoGL, see Reiter and Lutz (2019), as well as Lutz et al. (2018; 2021).

Figure 4 shows the difference between YoGL3 and YoGL at age 20 for males and females in all 38 benchmark countries. Irrespective of gender, the difference is larger in poorer countries, where more good years of life are lost due to a large share of the population living in poverty. In some countries (e.g. Thailand, Russia, Netherlands), the difference is close to zero, which suggests that everyone living in poverty is also below the threshold in at least one additional dimension.

\subsubsection{Relationship between YoGL3 (disregarding poverty) and life expectancy}

In the next step, we analyze the relationship between YoGL3 and life expectancy. By looking at how the proportion of "good" years (YoGL3/Life expectancy) changes with increasing life expectancy, we can estimate YoGL3 as a function of a country's development stage (proxied by life expectancy). As the proportion of good years is a fraction of total life expectancy, we use a fractional logit model for this purpose. Figure 5 depicts the resulting relationship by gender. In both cases, the fractional logit model fits the 38 observations quite well. In terms of gender differences, it is worth noting that the proportion of good years of total life expectancy at age 20 is consistently lower for females than for males. Based on these estimates, in a next step we predict YoGL3 for all countries and over time. ${ }^{1}$

\footnotetext{
1 Countries with a proportion of good years below 0.4 were excluded from the analysis. The unusually low YoGLs of these statistical outliers are mostly due to extremely high proportions of the population not passing the threshold in terms of basic numeracy and literacy. This can be explained by inter-cohort differences in access to education - particularly for women - rather than by actual cognitive inability. Including these cases would likely distort the results.
} 
Figure 4:

Difference in Years of Good Life between YoGL3 (disregarding poverty) and complete YoGL at age 20, 2010-14, 38 benchmark countries

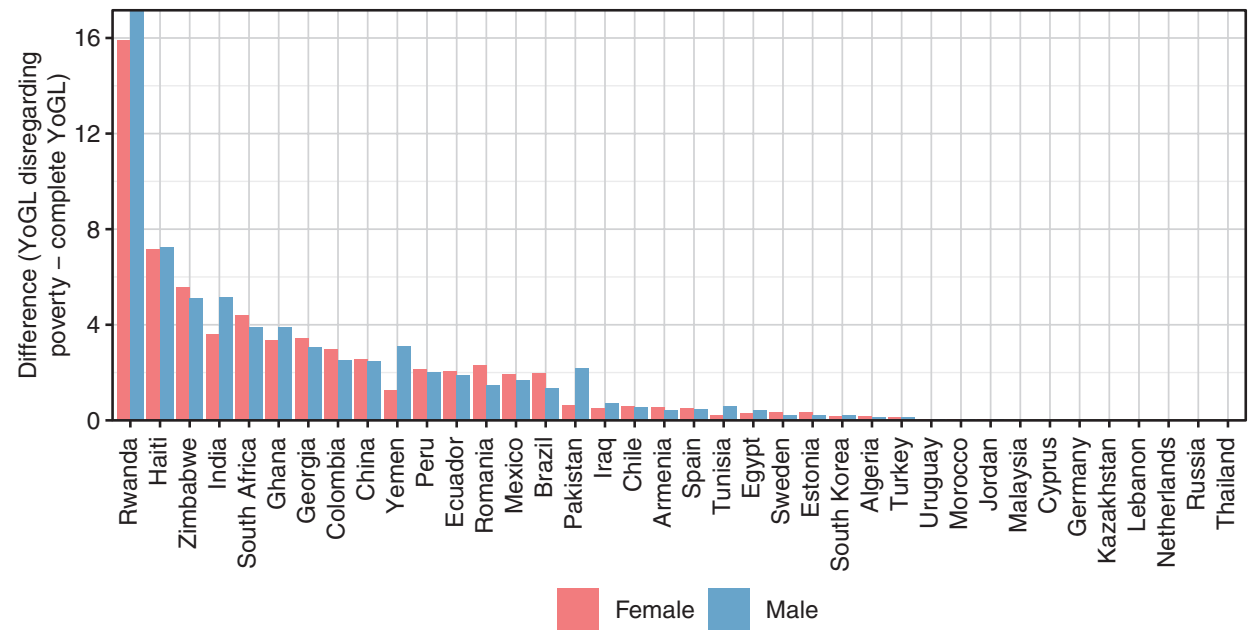

Source: Own calculations based on Lutz et al. (2021).

\section{Figure 5:}

Gender-specific relationship between the proportion of YoGL3 and overall life expectancy at age 20 in 2010-14 for 38 benchmark countries. Curves fitted based on a fractional logit model

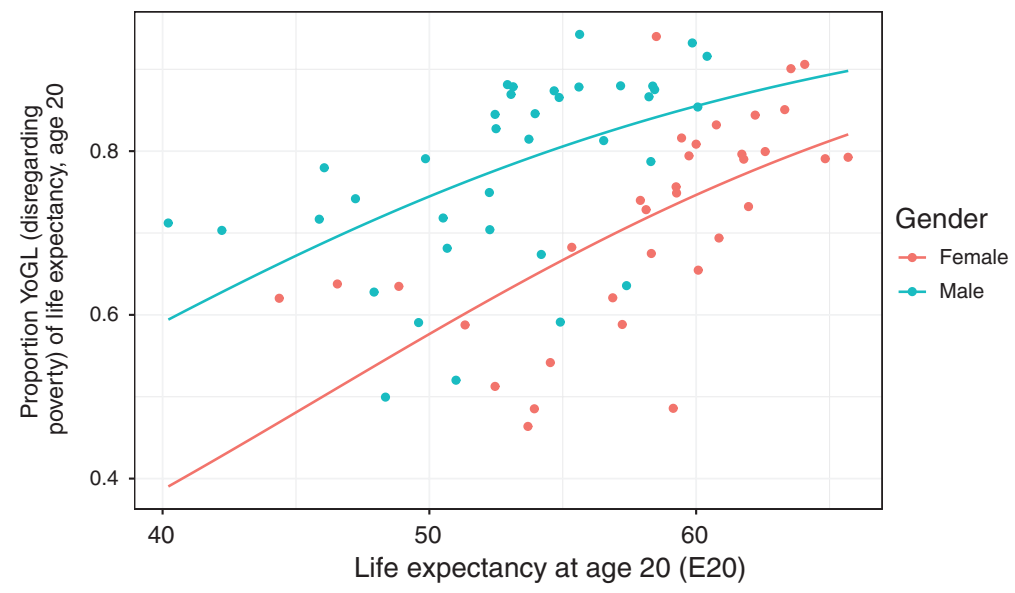

Source: Own calculations based on Lutz et al. (2021). 
Our aim of deriving time series estimates from data observed for 38 benchmark countries in the 2010-2014 period no doubt represents a challenge for our methodology. However, given the constraints imposed on us by data availability, basing our reconstruction of YoGL on data from countries that fulfill the data requirements set for YoGL is a reasonable solution. Our reconstructed time series continue to capture the understanding of human well-being enshrined in the original design of YoGL, while accounting for possible correlations between the YoGL sub-dimensions at the individual level. Nevertheless, we are aware that this solution does not fully reflect the impact of period- and country-specific events (e.g. wars, economic crises, etc.) on YoGL dimensions, apart from their impact on life expectancy and material well-being when the available economic data were used. Basing our estimates on countries that were at a similar stage of development (i.e. with a similar life expectancy) as the respective country in the respective year, and assuming that these estimates reflect similar YoGL characteristics, only partly resolves this issue.

\subsubsection{Adjusting for individual correlations}

When combining the YoGL3 estimates with the historical data on poverty, we have to make sure that we are not double-counting the loss in good years due to poverty. Many people who fail to meet the out-of-poverty criterion are most likely also below the threshold in at least one of the other three dimensions, and are thus already considered in the calculation of YoGL3. Therefore, we would unnecessarily bias YoGL downward by ignoring this possibility. Ideally, the entire derivation would rely on individual observations of all four YoGL dimensions for one and the same sample of individuals. However, as such historical, internationally harmonized time series do not exist, we have to derive YoGL on the aggregate level.

In order to account for the unobserved individual-level correlation, for each of the 38 benchmark countries where YoGL can be assessed empirically, we first multiply YoGL3 by the proportion of the population out of poverty (henceforth referred to as "poverty-intensive YoGL"). ${ }^{2}$ As shown in Figure 6, the gender-specific ratio between YoGL and poverty-intensive YoGL (both at age 20) is a declining function of the share of the population that is out of poverty (coefficient of correlation $=-0.94)$. The higher the proportion of people living in poverty, the more likely it is that poverty is the only dimension responsible for a loss in good years in a country. This is also reflected in Figure 4, which shows that the differences between YoGL3 and the complete YoGL are largest in poor countries. Exploiting this strong association, we therefore scale YoGL upward for each country and period using local polynomial regression in order to account for individual correlations between YoGL dimensions.

2 The calculation of "poverty-intensive YoGL" again follows the Sullivan method. 
Figure 6:

Relationship between the adjustment factor (YoGL/poverty-intensive YoGL) and the share of the population out of poverty in 2010-14 for 38 benchmark countries as fitted by local polynomial regression

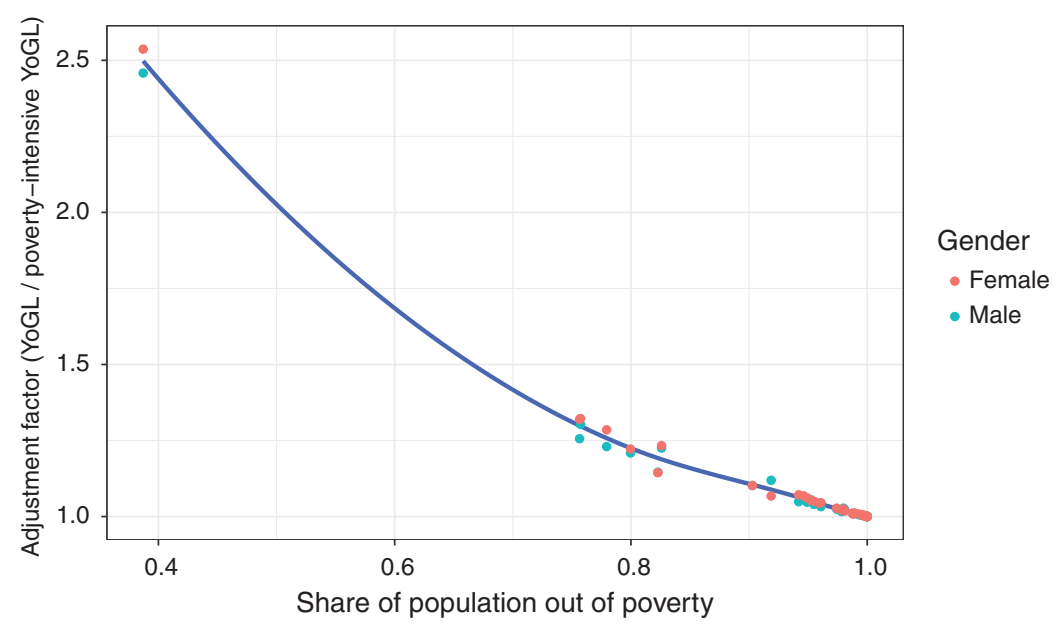

Source: Own calculations based on Lutz et al. (2021).

\subsubsection{Estimating YoGL at age 20}

The final step in our reconstruction of YoGL at age 20 from 1950 to 2015 for all countries where poverty estimates are available is described by the following formula:

$$
Y o G L_{c, y}^{20}=E_{c, y}^{20} * \frac{Y o G L 3_{c, y}^{20}}{E_{c, y}^{20}} * \text { frac_oop }_{c, y} * \text { adj_factor }_{c, y}
$$

where $Y o G L_{c, y}^{20}$ represents the predicted YoGL at age 20 for a given country $c$ in a given year $y ; E_{c, y}^{20}$ denotes life expectancy at age 20 for the same country and year; $Y o G L 3_{c, y}^{20} / E_{c, y}^{20}$ is the estimated proportion of good years (disregarding poverty) of total life expectancy as a function of $E_{c, y}^{20}$; frac_oop fry $_{\text {r }}$ denotes the estimated countryand time-specific out-of-poverty fraction; and adj_factor $_{c, y}$ represents the estimated adjustment factor (to account for individual-level correlations) as a function of frac_oop c,y $_{\text {. }}$ 
Table 1:

Years of Good Life (YoGL) at age 20 for women in the top-five and bottom-five countries in 1950, 1980 and 2010 , sorted by the 2010 ranking

\begin{tabular}{lrrr}
\hline & $\mathbf{1 9 5 0}$ & $\mathbf{1 9 8 0}$ & $\mathbf{2 0 1 0}$ \\
\hline Japan & 29.48 & 45.61 & 55.67 \\
Spain & 33.98 & 45.37 & 53.90 \\
France & 35.07 & 44.74 & 53.55 \\
Switzerland & 35.68 & 45.34 & 53.11 \\
Italy & 35.11 & 43.78 & 52.87 \\
Democratic Republic of the Congo & 4.14 & 5.91 & 19.04 \\
Mozambique & 9.47 & 14.49 & 18.03 \\
Central African Republic & 7.97 & 14.10 & 15.14 \\
Eswatini & 10.83 & 17.49 & 13.67 \\
Lesotho & 22.88 & 30.41 & 12.74 \\
\hline
\end{tabular}

Source: Own calculations.

\section{Results}

The result of applying this methodology is a global dataset of YoGL at age 20 for 140 countries from 1950 to $2015^{3}$ in five-year time intervals, which allows us to look at human development from a different angle. In this section, we present our estimates of YoGL, and compare them to other indicators of human well-being: namely, life expectancy and GDP per capita. While life expectancy is available for the majority of countries around the world as far back as 1950, only 53 countries provide sufficient information to enable us to reconstruct time series of GDP per capita this far into the past. This limits our understanding of how human development evolved prior to the 1970s, when consistent information on GDP per capita was becoming available through the Penn World Tables. Being based on life expectancy, YoGL can be reconstructed for a far larger number of countries back to 1950, while covering a much wider range of dimensions of human well-being than GDP per capita. Table 1 shows female YoGL at age 20 in 1950, 1980 and 2010 for the top-five and bottom-five countries, respectively, according to the YoGL ranking in 2010. World maps of female life expectancy and YoGL at age 20, as well as the log of GDP per capita, are shown in the Appendix.

While life expectancy and YoGL are generally correlated, we do find important differences between them. In China, for example, female life expectancy at age 20 rose from 40.6 years in 1950 to 54 years in 1980. However, this increase was far more noticeable in YoGL terms. While Chinese women who were 20 years

3 For some countries, poverty rates could not be estimated for the entire period. 
old in 1950 could, on average, expect to live another 12.8 good years; by 1980 , this figure had increased by a staggering $150 \%$ to 32 years, meaning that most of the increase in life expectancy experienced over that period indeed represented an increase in good years. Meanwhile, in India, female life expectancy at age 20 had increased from 35.2 years to 47.7 years. Over the same period, the increase in YoGL (16 years) exceeded the number of years that 20-year-old Indian women could expect to live in 1950 in total (9.5 years). By contrast, in some countries in the Global South, such as in Guinea and the Democratic Republic of the Congo, there were hardly any improvements in YoGL over the first three decades of the observation period, whereas life expectancy was steadily increasing, albeit at a slow pace. This stagnation in YoGL was predominantly due to the poverty dimension. The World Bank data that are available for 1980 onward show that there has been a much steeper decline in the proportion of people living in poverty in those countries since 1980 than the information reconstructed from the Bourguignon and Morrison data would suggest. Hence, assuming that the more recent information provided by the World Bank is more reliable, the initial 1950 poverty rates as reconstructed from Bourguignon and Morrison might be too high, and could lead to the overestimation of YoGL in these countries for the 1950-1980 period.

Another way of looking at this relationship is by mapping YoGL as a share of total life expectancy (Figure 7). Whereas in North America, Western Europe and Australia, up to almost $80 \%$ of all remaining life years at age 20 could be expected to be good years as far back as in 1950; in most countries in Sub-Saharan Africa, this level of quality of life still had not been reached by 2010 . The lowest value of this share, of only $10 \%$, was recorded for women in the Democratic Republic of Congo in 1950, when the country was still under Belgian colonial rule. By 2010, this value had increased to $38.6 \%$, but it still lagged far behind that in Japan, which was the global leader in terms of YoGL share. Thus, in 2010, 20-year-olds in Japan could expect to spend $84.3 \%$ of their remaining life years free from material, physical and cognitive deprivation, while subjectively perceiving these years as satisfying.

Because it is based on life expectancy, another major advantage of YoGL over GDP per capita is that it can be derived separately for men and women. The gender differences in YoGL, and how they change over time, can shed considerable light on the development process. While both YoGL and life expectancy increased globally over the observation period, and the global gender gap in YoGL (average over all countries) has been decreasing over time, strong gender disparities remain. In India, for example, YoGL at age 20 increased markedly as a share of life expectancy for both sexes. However, the increase for men from $46 \%$ in 1950 to $75 \%$ in 2010 was exceeded by that for women, as the YoGL gender gap decreased by almost eight percentage points over the same time period, which resulted in $64 \%$ of women's remaining life years at age 20 in 2010 being YoGL. Similarly in China, women have been catching up to men in recent decades. Still, as they started from a much lower level, women's share of YoGL in life expectancy at age 20 in 2010 was still $9.2 \%$ lower than that of men. 
Figure 7:

Share of remaining good years in life expectancy at age 20 by gender, 1950, 1980, 2010
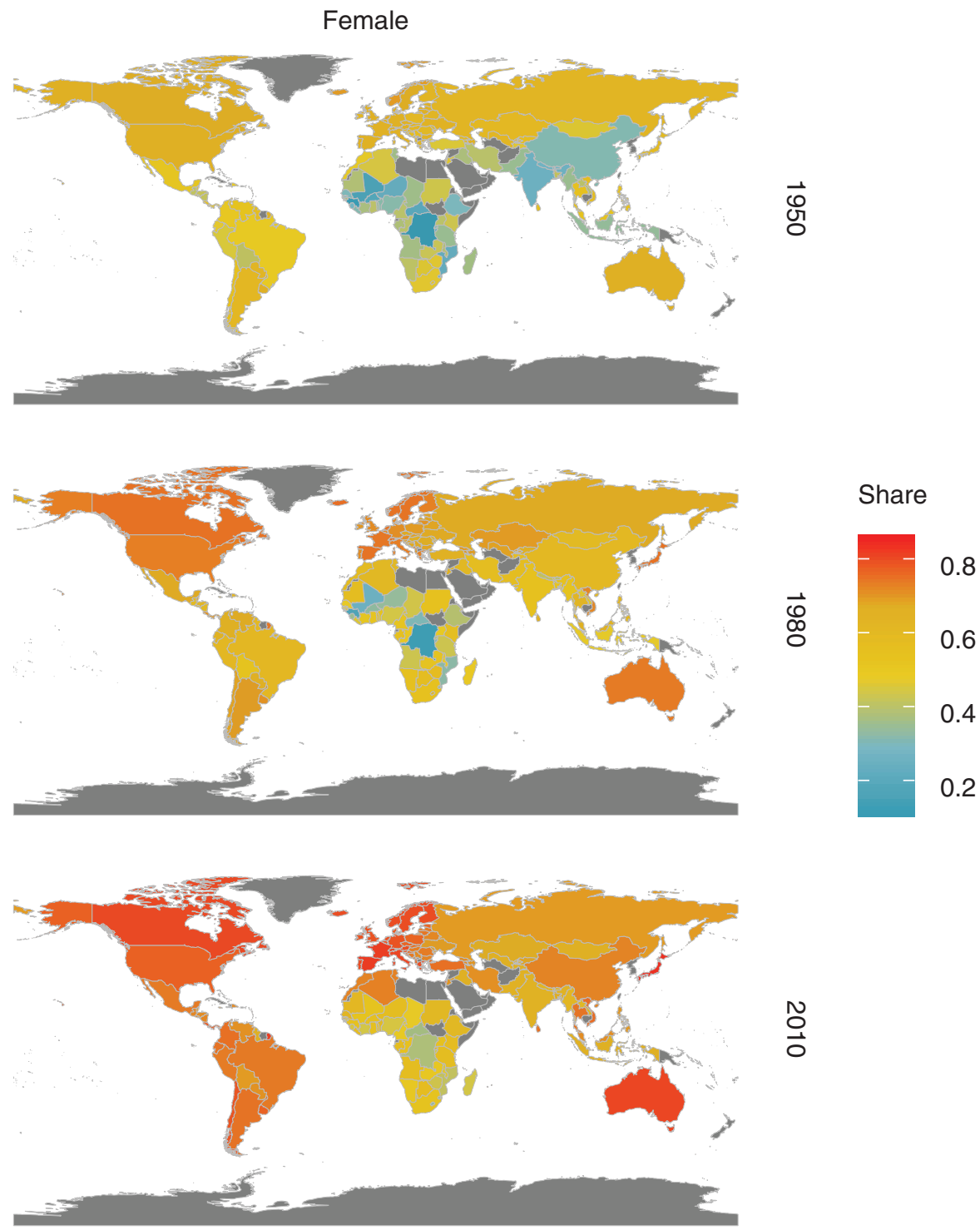

$\frac{N}{0}$

Further telling comparisons can be made by world regions. As shown in Figure 8, which depicts YoGL at age 20 for men vs. women for individual countries grouped into world regions, significant progress has been made in all world regions, not just toward increases in the share of YoGL in life expectancy, but toward increases 
Figure 7:

Continued
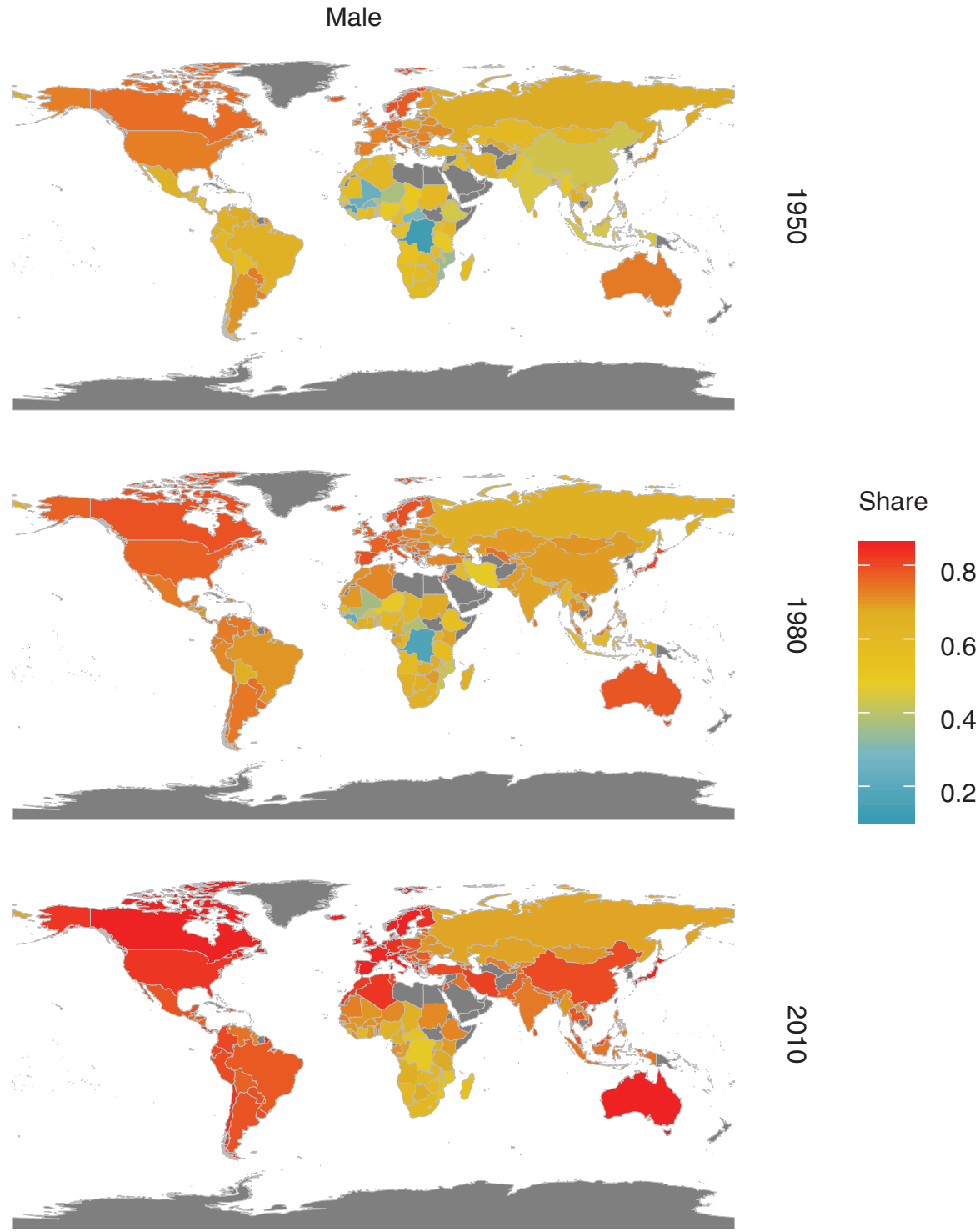

$\stackrel{\text { 옹 }}{\circ}$

Source: Own calculations.

in overall YoGL for both sexes. The countries that are still characterized by relatively low YoGL at age 20 in 2010 can be found predominantly in Africa. The disadvantages for females in YoGL are largest in Africa and Southwest Asia. Among the highly developed countries, most of which are in Europe and North America, we 


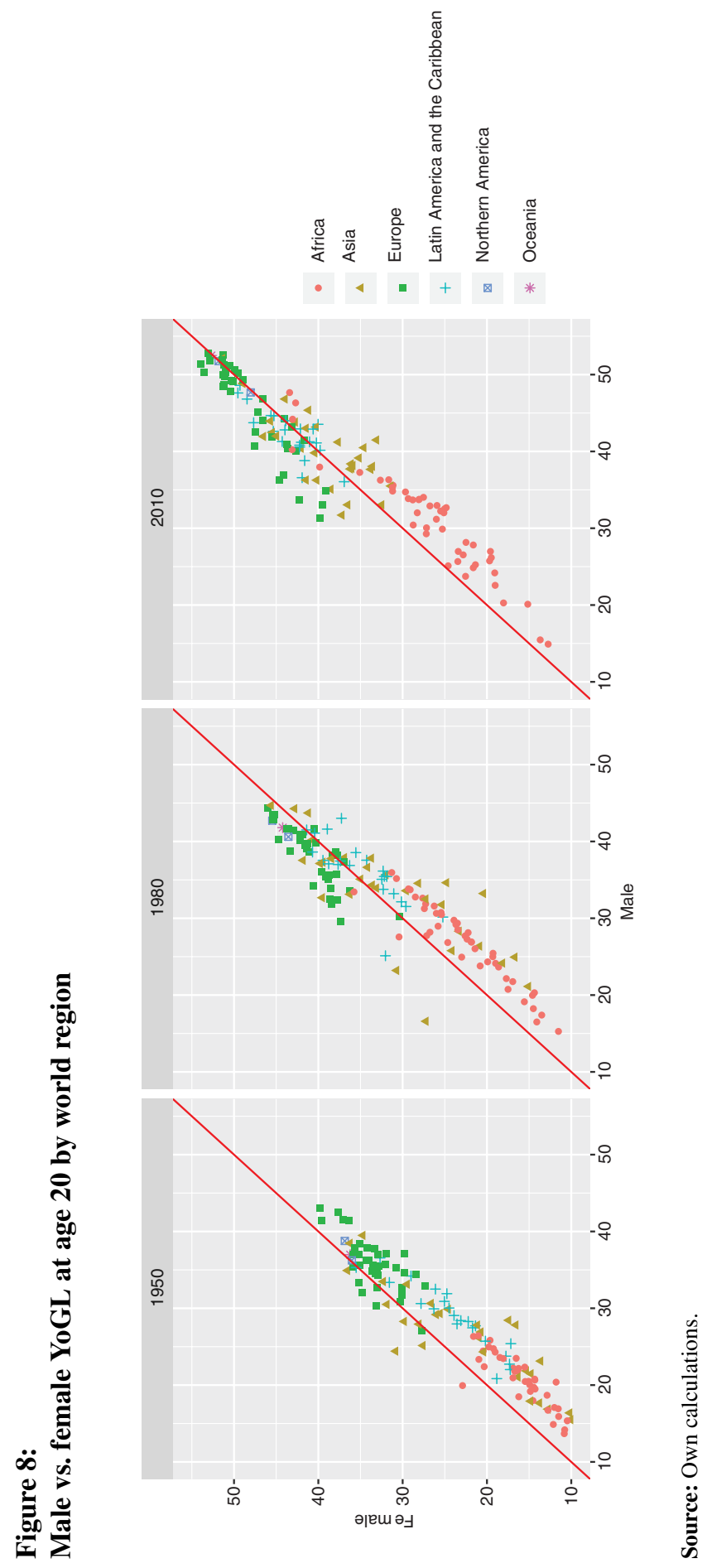


find both smaller differences between YoGL and life expectancy, and slight gender disparities in favour of women. While major gender pay gaps continue to persist in many of these highly developed countries, the female disadvantage in YoGL observed at lower stages of development seems to have reversed in these countries, following the emergence of a slightly positive relationship between life expectancy and the gender gap in YoGL (female minus male YoGL).

Similar results on gender disparities were reported in a separate project on estimating YoGL at age 50 for Europeans (Wittgenstein Centre for Demography and Global Human Capital 2020). While YoGL in 2015 was found to be quite similar for women and men, with a slight advantage for women (consistent with the findings presented in Figure 8); due to higher female life expectancy, women still had fewer "good years" relative to men. These results are related to the male-female health-mortality paradox (di Lego et al. 2019), which describes the phenomenon that women live longer than men, but spend a larger proportion of their life in poorer health (Luy and Minagawa 2014; Pongiglione et al. 2015).

\section{Discussion and Outlook}

Criticizing conventional indicators of human well-being for how they assess improvements in quality of life over time has become a common refrain in the literature (Stiglitz et al. 2010; Laurent 2017). Yet for lack of better alternatives, particularly when looking into the more distant past, they continue to be widely used. In this article, we present an alternative. The Years of Good Life (YoGL) indicator, as recently introduced by Lutz et al. $(2018 ; 2021)$, represents the number of years a person can expect to live as part of a specific sub-population without serious limitations in her material, physical, cognitive and subjective well-being. YoGL addresses many of the shortcomings of GDP per capita, life expectancy and the human development index (HDI). But while the merits of this new, demographybased approach to evaluating QOL are described in more detail elsewhere (Lutz et al. 2021), here, we have presented the first attempt to consistently reconstruct genderspecific YoGL for 140 countries of the world going back to 1950 .

This time span is, of course, not nearly as long as the recent reconstruction of YoGL for Finland to 1860 by Reiter and Lutz (2019). Yet since no other country in the world provides data ranging back more than 150 years, our reconstruction based on available international time series on longevity from the World Population Prospects (United Nations 2019), reconstructed poverty headcount ratios as provided by Bourguignon and Morrisson (2002), as well as previous derivations of YoGL for a much smaller group of countries in the more recent past (Lutz et al. 2021) - marks the boldest effort so far to enable country comparisons of QOL going back 70 years.

These reconstructed time series provide a basis for reevaluating past development trajectories with respect to their sustainability. Only if YoGL does not decline for a specific (sub-) population over time - i.e. for subsequent generations - can 
development be referred to as sustainable. While in terms of GDP per capita, the exploitative extraction of natural resources would invariably indicate an improvement in human well-being, our newly reconstructed time series of YoGL can help us detect the possible negative effects on human well-being that the related losses in biodiversity and environmental quality may have had due to their effects on life expectancy, as well as through the ensuing deterioration in the health dimension of YoGL. Likewise, while GDP per capita neglects distributional aspects, growing inequality would result in lower YoGL due to lower subjective well-being among a society's poorer members. In practice, of course, data quality remains an issue. But our reconstruction of YoGL represents an important first step toward gaining an improved understanding of the extent to which human development in the past evolved sustainably.

Going forward, our intention is to use these reconstructed time series of YoGL as the dependent variable in a well-being production function (Levin and Clark 2010; Clark 2012; Polasky et al. 2015; Irwin et al. 2016). Similar to the conventional growth-accounting framework that is used to explain why some nations surge ahead in terms of GDP while others fall behind, we aim to find the reasons why human well-being is so much higher in some countries than in others. Whereas growthaccounting typically fails to account for the potentially negative feedback effects of economic growth, our reconstructed time series of YoGL allow us to investigate how human well-being has indeed been affected by the collateral damage of economic growth since the second half of the $20^{\text {th }}$ century. Once we have estimated the well-being production function, we can further use it to make predictions about future human well-being under different socioeconomic scenarios; e.g. the Shared Socioeconomic Pathways (SSPs, O'Neill et al. 2017; KC and Lutz 2017).

The major limitations of our reconstruction are mostly associated with a lack of data. In comparison to the indicators necessary for monitoring progress in the full set of Sustainable Development Goals (Maurice 2016), YoGL is an extremely parsimonious alternative. However, despite its rather austere data requirements, sticking to the original YoGL recipe remains a challenge. Internationally consistent efforts to collect data for individual dimensions of YoGL, let alone for all of them at once, have so far hardly been undertaken. Given the strengths of the YoGL indicator, we very much hope that future surveys will include the important dimensions of human well-being needed for its construction. At the same time, our reconstruction was able to rely on the most essential dimension of human well-being, which is being alive; and we were able to provide estimates of the poverty dimension, while accounting for its correlation with the remaining unobserved YoGL dimensions, and thus maintaining the critical relations YoGL aims to account for.

Another important limitation of our analysis lies in the scope and the quality of the data that we were using. For the reconstruction of three out of the four YoGL dimensions, we relied on a relatively narrow set of countries for which data are available from the recent past. In the case of the fourth dimension (being out of poverty), no recent attempts have been made to provide historical time series consistent with the information provided by the World Bank based on household 
survey data starting in 1980. For a few developing countries that started out with very high poverty prevalence rates in 1950 , our reliance on the poverty headcount ratios provided by Bourguignon and Morrisson (2002) led to regime breaks in the pace of development when moving from the older to the more recent and more reliable data sources on poverty. Furthermore, as no information on the age- and gender-specific prevalence of poverty is available, we used country-wide poverty rates for both males and females.

Nonetheless, it is important to note that the idea of human well-being, as embodied by the YoGL indicator, focuses mostly on the tail end of the distribution in each of the four well-being dimensions. Hence, not knowing the precise shape of the complete distribution for each of the YoGL dimensions is less likely to have affected the accuracy of our reconstruction than if the underlying longevity estimates had been inaccurate, since YoGL is primarily a refined version of life expectancy, and the extra dimensions only serve the purpose of identifying which of the total years lived in a population actually qualify to be counted as good years.

In addition, as representative global survey data on the components of YoGL are not available as far back as 1950, our reconstruction also failed to meet the requirement that YoGL should be derived "from the bottom up"; i.e. from individuallevel observations. It is this requirement that makes YoGL flexibly applicable, not just to the aggregate country level, but also to specific, well-defined subpopulations for whom life table information does exist, such as men vs. women. However, we provide a reasonable solution for the resulting problem of unobserved individual-level correlations between the different YoGL dimensions by rescaling YoGL based on the empirical relationship between the loss of good years solely due to poverty and the overall share of the population above the poverty line. Given the strength of this relationship, we are confident that we are maintaining the essential characteristics of YoGL.

\section{References}

Atkinson, A. B. 1975. The economics of inequality. Clarendon Press.

Börsch-Supan, A., K. Hank and H. Jürges 2005. A New Comprehensive and International View on Ageing: Introducing the 'Survey of Health, Ageing and Retirement in Europe.' European Journal of Ageing 2(4): 245-53. https://doi.org/10.1007/s10433-005-0014-9

Bourguignon, F. and C. Morrisson 2002. Inequality among World Citizens: 1820-1992. The American Economic Review 92(4): 727-44. https://doi.org/10.1257/00028280260344443

Clark, W. C. 2012. Sustainability Science: Its Origins, Evolution and Challenges. Presented at the IIASA 40th Anniversary Conference, Vienna, Austria, 25 October 2012. http: //conference2012.iiasa.ac.at/person.html?code $=$ clark\&scode $=\mathrm{s} 2 \mathrm{~s} 7$

Desai, M., A. Sen and J. Boltvinik 1992. Social progress index: A proposal. Bogota: United Nations Development Programme.

Diener, E. 1984. Subjective well-being. Psychological Bulletin 95(3): 542-75. https://doi. org/10.1037/0033-2909.95.3.542 
di Lego, V., P. Lazarevič and M. Luy 2019. The male-female health-mortality paradox. In Encyclopedia of Gerontology and Population Aging, eds D. Gu and M. E. Dupre, 1-8. Cham: Springer International Publishing. https://doi.org/10.1007/978-3-319-698922_798-2

Easterlin, R. A. 1974. Does Economic Growth Improve the Human Lot? Some Empirical Evidence. In Nations and Households in Economic Growth, eds P. A. David, M. W. Reder, 89-125. Elsevier. https://doi.org/10.1016/B978-0-12-205050-3.50008-7

European Commission, and Statistical Office of the European Union 2018. Living Conditions in Europe: 2018 Edition. https://doi.org/10.2785/39876

Eurostat 2020. Life Expectancy by Age, Sex and Educational Attainment Level. http://appsso. eurostat.ec.europa.eu/nui/show.do?dataset=demo_mlexpecedu\&lang=en

Ghislandi, S., W. C. Sanderson and S. Scherbov 2019. A simple measure of human development: The human life indicator. Population and Development Review 45(1): 219-33. https://doi.org/10.1111/padr.12205

Helliwell, J. F., R. Layard and J. Sachs (eds) 2012. World Happiness Report. The Earth Institute - Columbia. https://worldhappiness.report/ed/2012/

Inglehart, R. 1990. World Values Survey, 1981-1983. Inter-university Consortium for Political and Social Research.

Irwin, E. G., S. Gopalakrishnan and A. Randall 2016. Welfare, wealth, and sustainability. Annual Review of Resource Economics 8(1): 77-98. https://doi.org/10.1146/annurevresource-100815-095351

KC, S. and W. Lutz 2017. The human core of the shared socioeconomic pathways: population scenarios by age, sex and level of education for all countries to 2100. Global Environmental Change 42(January): 181-92. https://doi.org/10.1016/j.gloenvcha.2014.06. 004

Kowal, P., S. Chatterji, N. Naidoo, R. Biritwum, Fan Wu, R. Lopez Ridaura, T. Maximova, et al. 2012. Data resource profile: the world health organization Study on Global AGEing and Adult Health (SAGE). International Journal of Epidemiology 41(6): 1639-49. https: //doi.org/10.1093/ije/dys210

Laurent, É. 2017. Measuring tomorrow: Accounting for well-being, resilience, and sustainability in the twenty-first century. Princeton University Press.

Levin, S. A. and W. C. Clark 2010. Toward a science of sustainability. CID Working Papers 196. Center for International Development at Harvard University. https://ideas. repec.org/p/cid/wpfacu/196.html

Lok-Dessallien, R. 2000. Review of Poverty Concepts and Indicators. Chicago: Academic Press. https://pdfs.semanticscholar.org/a358/eb2139bf8c50b338863d0ecb63d4c6dedb21. pdf

Lutz, W., A. A. Lijadi, E. Striessnig, A. Dimitrova and M. Caldeira Brant de Souza Lima 2018. Years of Good Life (YoGL): A New Indicator for Assessing Sustainable Progress. IIASA Working Paper WP-18-007. Laxenburg, Austria: International Institute for Applied Systems Analysis. http://pure.iiasa.ac.at/id/eprint/15402/

Lutz, W., E. Striessnig, A. Dimitrova, S. Ghislandi, A. A. Lijadi, C. Reiter, S. Spitzer and D. Yildiz 2021. Years of Good Life (YoGL) is a Wellbeing Indicator Designed to 
Serve Research on Sustainability. Proceedings of the National Academy of Sciences. https://doi.org/10.1073/pnas.1907351118

Luy, M. and Y. Minagawa 2014. Gender gaps-life expectancy and proportion of life in poor health. Health Reports 25(12): 12-19.

Maurice, J. 2016. Measuring progress towards the SDGs-a new vital science. The Lancet 388(10053): 1455-58. https://doi.org/10.1016/S0140-6736(16)31791-3

Nieuwenhuis, R., T. Munzi, J. Neugschwender, H. Omar and F. Palmisano 2018. Gender equality and poverty are intrinsically linked: A contribution to the continued monitoring of selected sustainable development goals. United Nations entity for gender equality and the empowerment of women. https://www.unwomen.org/digital-library/publications/2018/12/ discussion-paper-gender-equality-and-poverty-are-intrinsically-linked

O’Neill, B. C., E. Kriegler, K. L. Ebi, E. Kemp-Benedict, K. Riahi, D. S. Rothman, B. J. van Ruijven, D. P. van Vuuren, J. Birkmann, K. Kok, M. Levy and W. Solecki 2017. The roads ahead: narratives for shared socioeconomic pathways describing world futures in the 21st century. Global Environmental Change 42(January): 169-80. https://doi.org/10. 1016/j.gloenvcha.2015.01.004

Polasky, S., B. Bryant, P. Hawthorne, J. Johnson, B. Keeler and D. Pennington 2015. Inclusive wealth as a metric of sustainable development. Annual Review of Environment and Resources 40(1): 445-66. https://doi.org/10.1146/annurev-environ-101813-013253

Pongiglione, B., B. L. De Stavola and G. B. Ploubidis 2015. A systematic literature review of studies analyzing inequalities in health expectancy among the older population. PLoS ONE 10(6): e0130747. https://doi.org/10.1371/journal.pone.0130747

Reiter, C. and W. Lutz 2019. Survival and years of good life in Finland in the very long run. Finnish Yearbook of Population Research 54: 1-27. https://doi.org/10.23979/fypr.87148

Roser, M. and E. Ortiz-Ospina 2013. Global extreme poverty. Our World in Data, May. https://ourworldindata.org/extreme-poverty

Sen, A. 1983. Poor, relatively speaking. Oxford Economic Papers 35(2): 153-69. https: //doi.org/10.1093/oxfordjournals.oep.a041587

Siposne Nandori, E. 2014. Objective and subjective poverty. In Encyclopedia of quality of life and well-being research, ed A. C. Michalos, 4424-28. Dordrecht: Springer Netherlands. https://doi.org/10.1007/978-94-007-0753-5_3779

Stiglitz, J. E., J. P. Fitoussi and A. Sen 2010. Mismeasuring our lives: Why GDP doesn't add up. New York: The New Press. https://thenewpress.com/books/mismeasuring-our-lives

Streeten, P. 1990. Poverty concepts and measurement. The Bangladesh Development Studies 18(3): 1-18. https://www.jstor.org/stable/41968775

United Nations 2019. World Population Prospects: The 2019 Revision. New York, NY: Department of Economic and Social Affairs, Population Division. http://esa.un.org/unpd/ wpp/

Wittgenstein Centre for Demography and Global Human Capital. 2020. European Demographic Data Sheet 2020. Vienna: Wittgenstein Centre (IIASA, OeAW, University of Vienna). http://www.populationeurope.org/en/download/EDS2020_POSTER.pdf

World Bank. 2017. World Development Indicators. Washington D.C.: The World Bank. https://data.worldbank.org/products/wdi 


\section{Appendix}

Figure A1(a):

World maps of female life expectancy at age 20 (a), female YoGL at age 20 (b) and the $\log$ of GDP per capita (c) in 1950, 1980 and 2010.

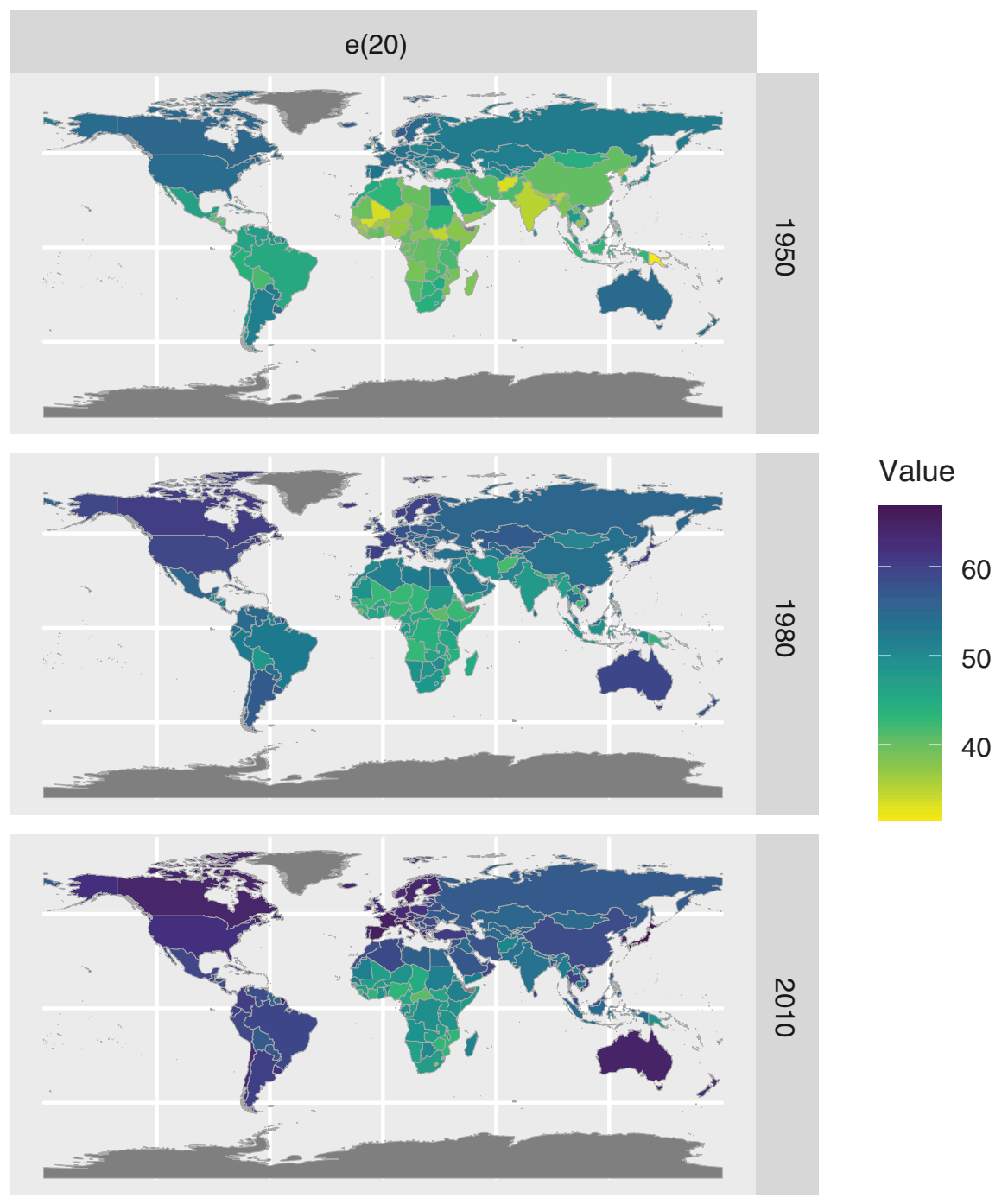


Figure A1(b):
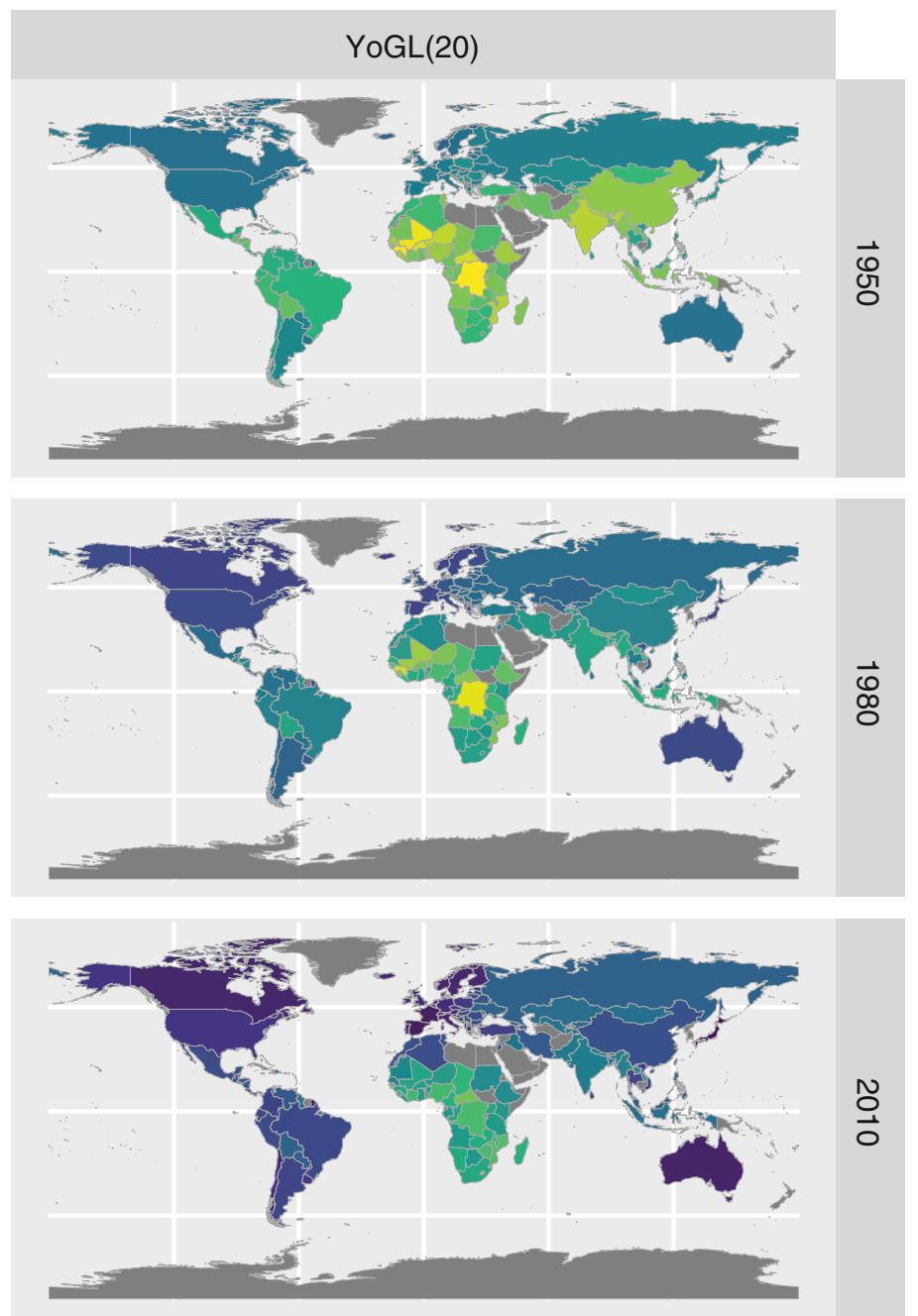

Value

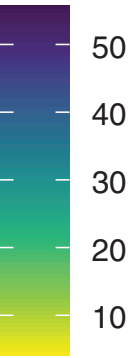




\section{Figure A1(c):}

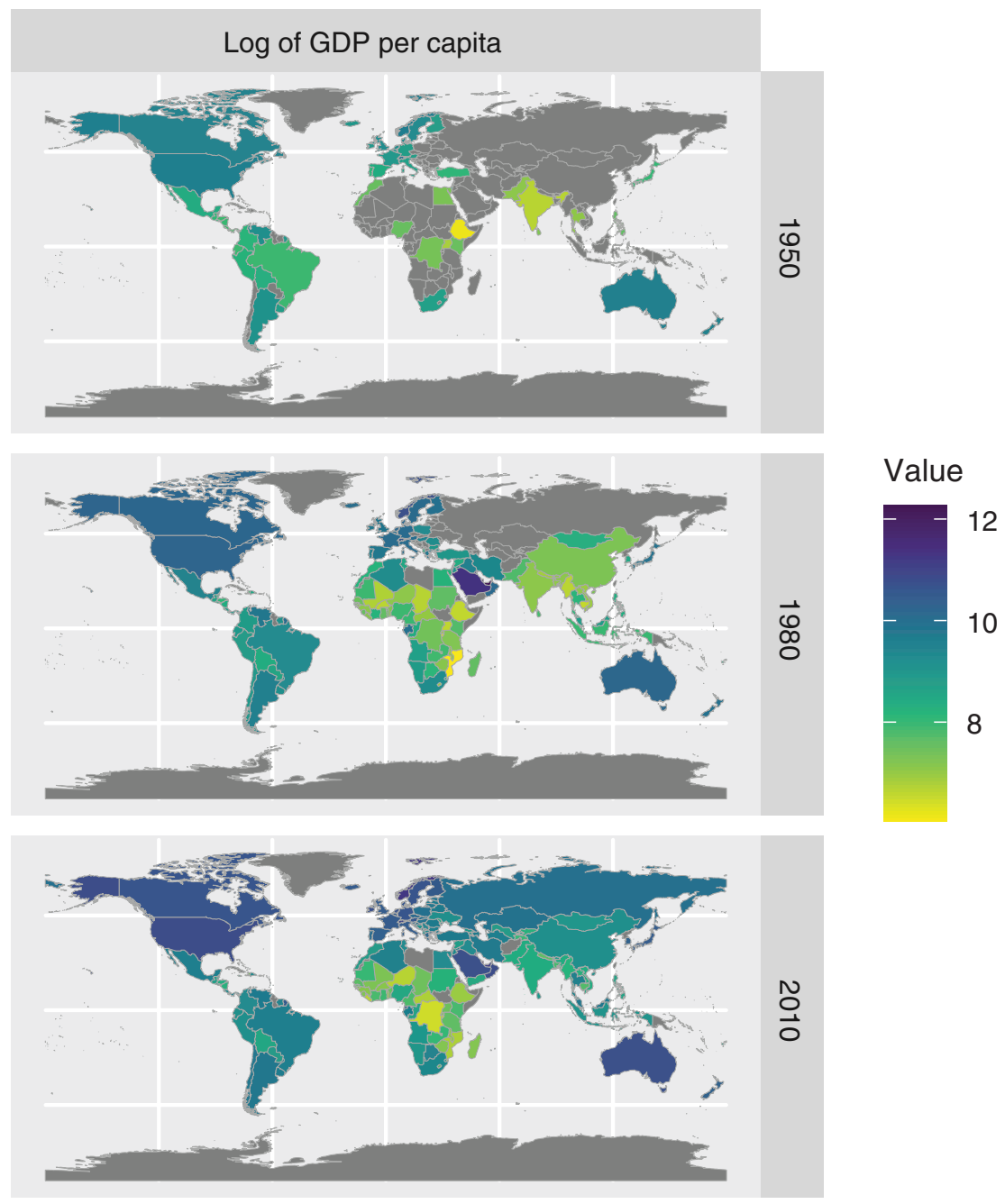

Source: UN World Population Prospects, Penn World Tables 9.1, and own calculations.

Open Access This article is published under the terms of the Creative Commons Attribution 4.0 International License (https://creativecommons.org/licenses/by/4.0/) that allows the sharing, use and adaptation in any medium, provided that the user gives appropriate credit, provides a link to the license, and indicates if changes were made. 